


\section{Utilização de revestimento comestível à base de quitosana para aumentar a vida útil de melão minimamente processado.}

\section{Edible coating utilization the chitosan base to improve melon shelf life minimally processed}

\section{OPPEN ACCESS}

\author{
Raquel Costa Chevalier ${ }^{1, \text { (iD }}$ \\ Gisele Fernanda Alves da Silva ${ }^{2, \text { (iD }}$ \\ Denize Marques da Silva ${ }^{1,(1 D}$ \\ Sandriane Pizato ${ }^{1,(1 D}$ \\ William Renzo Cortez-Vega ${ }^{1, *}$ (iD \\ 1 Universidade Federal da Grande \\ Dourados-UFGD, Dourados, MS, Brasil. \\ 2 Universidade Estadual Paulista, Júlio de \\ Mesquita Filho - UNESP, São José do Rio \\ Preto, SP, Brasil \\ *Autor para correspondência: \\ williamvega@ufgd.edu.br
}

\section{Informações adicionais}

Recebido em: 07/04/2016

Aceito em: $10 / 08 / 2016$

Publicado em: 30/09/2016

Editor:

Victor Hugo Gomes Sales

Instituto Federal do Amapá. Macapá, Amapá, Brasil.jbfs@ifap.edu.br

\section{Avaliação às cegas por pares}

Protocolos de revisão

Prot. 1012016R01

Prot. $1012016 R 02$

Prot. 1012016R03

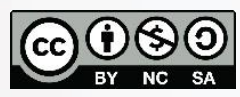

JBFS all rights

Copyright: (C) 2016
ID JBFS1012016

DOI 10.18067/jbfs.v3i3.101

\section{RESUMO}

Revestimentos comestíveis podem contribuir para aumentar a vida útil de frutas minimamente processadas reduzindo a umidade e a migração do soluto, a troca gasosa, respiração e velocidades de reação de oxidação, bem como reduzir distúrbios fisiológicos. O objetivo deste estudo foi avaliar os efeitos da aplicação de quitosana associada com argila montmorillonita e óleo essencial de cravo, em relação às características físicas, químicas, microbiológicas e atributos sensoriais de melão (Cucumis melo L.) minimamente processado quando armazenados a $4^{\circ} \mathrm{C}$. Os melões foram lavados, descascados, retiradas as sementes, cortados em cubos, foi aplicado os revestimentos e em seguida os cubos foram armazenados em embalagem PET (politereftalato de etileno), por um período de 7 dias a $4 \pm 1^{\circ} \mathrm{C}$. Realizaram-se análises de $\mathrm{pH}$, sólidos solúveis totais, acidez titulável, análises microbiológicas (Escherichia coli, Salmonella, bolores e leveduras) e análise sensorial (textura, cor, aroma, avaliação global). As análises foram realizadas em triplicata no dia do processamento (dia 0) e após 1, 3, 5 e 7 dias de armazenamento. Pode-se concluir que os revestimentos que continham quitosana juntamente com argila montmorillonita e quitosana juntamente com montmorillonita e óleo essencial de cravo (T3 e T4) foram mais eficientes na conservação das características físico-químicas de melão minimamente processado quando comparados com a amostra controle e o tratamento que continha somente quitosana. O uso de quitosana isoladamente e juntamente com montmorillonita e óleo essencial de cravo foram eficientes para manter as características sensoriais e microbiológicas por mais tempo.

Palavras-chave: Revestimento comestível. Cucumis. Montmorillonita. Óleo essencial.

\section{ABSTRACT}

Edible coatings may contribute to extend the shelf life of fresh-cut fruits by reducing moisture and solute migration, gas exchange, respiration, and oxidative reaction rates, as well as by reducing physiological disorders. The objective of this study was to evaluate the effects of chitosan application associated with montmorillonite clay and essential oil of cloves in relation to chemical, physical, microbiological (Escherichia coli, Salmonella and Yeast and Mold) and sensory attributes characteristics of melon (Cucumis melo L.) minimally processed when stored at $4 \pm 1^{\circ} \mathrm{C}$. The melons were washed, peeled, seeds removed, diced, was applied coatings and then the cubes were stored in a PET (polyethylene terephthalate) packaging for a period of 7 days at $4 \pm 1^{\circ} \mathrm{C}$. Analyses of $\mathrm{pH}$, total soluble solids, titratable acidity, microbiological (Escherichia coli, Salmonella, Molds and Yeasts) and sensory analysis (texture, color, aroma and overall assessment) were carried out. The analyses were performed in triplicate on the processing day (day 0 ) of the samples and after 1, 3, 5 and 7 days of storage. It can be concluded that the that coatings containing chitosan together with Montmorillonite clay and essential oil of clove (T3 and T4) were more efficient in conserving the physical and chemical characteristics of minimally processed melon when compared to the control sample and treatment contained only chitosan. The use of chitosan alone and together with montmorillonite and Clove essential oil were effective in maintaining the sensory and microbiological characteristics for a longer time.

Keywords: Edible coating. Melon. Montmorillonite. Essential oil. 


\section{INTRODUÇÃO}

As frutas minimamente processadas são produzidas a partir de vegetais frescos, e o processamento mínimo acelera a perecibilidade devido ao aumento das atividades metabólicas e descompartimentalização de enzimas e substratos. ${ }^{1}$

O melão (Cucumis melo L.) é uma espécie polimórfica, cujas formas botânicas diferenciam-se quanto aos aspectos de sensibilidade ao frio, capacidade de conservação, atividade metabólica e, sobretudo em forma, tamanho de fruto e estrutura da casca e da polpa. A casca apresenta variação de coloração que vai desde o laranja escuro até branco e verde, em função da cultivar ${ }^{2}$. O melão é um fruto bastante promissor para a obtenção de produto minimamente processado por ser pouco conveniente para uso individual em função do tamanho relativamente grande, casca e sementes. Desta forma, o desenvolvimento de técnicas que o tornem conveniente, que mantenham sua qualidade nutricional e sensorial, sua segurança e que estendam sua vida pós-colheita e pós-corte devem ser estudadas. ${ }^{2}$

Qualidade e vida útil de frutas minimamente processadas são reduzidas pelo processo de senescência, crescimento microbiano e perda de água, causados pelo descascamento e corte. ${ }^{3,4} \mathrm{~A}$ perda de água não resulta apenas na perda de peso, mas causa também mudanças indesejáveis na aparência, textura e qualidade nutricional do fruto. ${ }^{5}$ A perda da integridade do fruto durante as operações de processamento mínimo acelera as alterações fisiológicas e libera exsudato rico em nutrientes para o crescimento de fungos e bactérias deteriorantes, além de possibilitar contaminação através da manipulação sob condições inadequadas, reduzindo, desta forma a qualidade e a vida útil do produto, podendo o mesmo constituir um risco à saúde do consumidor. Logo, técnicas adequadas de conservação devem ser adotadas visando a preservação da qualidade dos produtos. ${ }^{6}$

Revestimentos comestíveis têm sido utilizados na indústria de minimamente processados como uma estratégia para reduzir os efeitos que o processamento mínimo provoca nos tecidos vegetais. Além disso, revestimentos comestíveis podem contribuir para aumentar a vida útil de fruas minimamente processadas, reduzindo a umidade e a migração do soluto, troca gasosa, respiração e reação de oxidação, bem como pode auxiliar na redução de distúrbios fisiológicos. ${ }^{7}$ Enquanto isso, o consumo de frutas frescas tem aumentado devido a demanda por alimentos frescos, saudáveis, convenientes e sem aditivos. $^{8}$

A quitosana é um polímero natural derivado do processo de desacetilação da quitina. É uma substância que tem sido empregada em filmes antimicrobianos por apresentar ação bactericida e fungicida ${ }^{9}$. É tido como o segundo polissacarídeo mais abundante da natureza, atrás apenas da celulose. Sua estrutura é formada pela repetição de unidade beta $(1,4)$ 2-amino-2-desoxi D-glucose e apresenta uma cadeia polimérica quimicamente similar à da celulose. Devido a suas características atóxicas e de fácil formação de géis, a quitosana tem sido considerada há décadas como um composto de interesse industrial. ${ }^{10}$

A montmorilonita é um mineral argiloso originário da erosão de cinza vulcânica que por ser polar, não é compatível com a maioria dos polímeros que são menos polares ou apolares e, portanto, deve ser modificada. Para tanto, são utilizados agentes compatibilizantes que se ligam à superfície da montmorillonita e que vão interagir com a resina para formar um sistema miscível, sendo esta compatibilização um dois maiores desafios para utilização de nanocompósitos. ${ }^{11}$ Diferente das argilas comumente utilizadas como reforços de plásticos, como a mica e o talco, a montmorilonita pode ser delaminada e incorporada na resina em camadas individuais com espessuras da ordem de $1 \mathrm{~nm}$, formando os nanocompósitos e ajudando nas propriedades dos filmes. ${ }^{12}$ Devido as mudanças nas propriedades dos filmes é que se optou pelo uso da montmorillonita neste estudo.

Os óleos essenciais são compostos complexos naturais, voláteis, caracterizados por um forte odor e constituído por metabólitos secundários de plantas aromáticas. Eles são normalmente obtidos por meio de vapor ou hidrodestilação. Conhecido pela sua atividade anti séptica, ou seja, bactericida, fungicida e virucida, propriedades medicamentosas e flavorizantes, eles são usados na conservação dos alimentos, como antibióticos, analgésicos e anti-inflamatório. Até os dias atuais, essas características não se alteraram muito, exceto que agora são mais conhecidos alguns de seus mecanismos de ação, particularmente para o efeito antimicrobiano. ${ }^{13}$ 
Geralmente os componentes majoritários determinam as propriedades biológicas dos óleos. A utilização do óleo essencial de cravo neste trabalho, tem por objetivo analisar que se além diminuir o crescimento microbiano, ele possa trazer alguns benefícios em relação a perda de qualidade de frutas minimamente processadas.

Com isso o objetivo desse trabalho foi avaliar a qualidade de melão (Cucumis melo L.) minimamente processado submetidos a três tratamentos à base de quitosana armazenados durante 7 dias a uma temperatura de $4 \pm 1^{\circ} \mathrm{C}$.

\section{MATERIAL E MÉTODOS}

\section{A) Material}

Foram utilizados melões amarelos (Cucumis melo L.) adquiridas no comércio local da cidade de Dourados, MS. As frutas foram selecionadas quanto ao peso (aproximadamente $1,5 \mathrm{~kg}$ ), e a maturação da casca (80\%). Os melões foram transportados em caixas de isopor até o laboratório de bioengenharia da Universidade Federal da Grande Dourados, onde foram armazenadas a $4 \pm 1^{\circ} \mathrm{C}$ durante 12 horas, até a realização do processamento mínimo.

\section{B) Preparo dos melões minimamente processados}

O processamento foi realizado à temperatura de, aproximadamente $10^{\circ} \mathrm{C}$, com os utensílios previamente higienizados em solução de cloro orgânico (dicloroisocianurato de sódio), na concentração de $2 \mathrm{~g} \cdot \mathrm{L}^{-1}$.

Os melões foram higienizados com solução de cloro orgânico a 2 g. $\mathrm{L}^{-1}$, por 10 minutos. A matéria-prima foi submetida à remoção manual da casca e sementes, sendo cortada, manualmente, em pedaços de aproximadamente $2,5 \times 2,5 \mathrm{~cm}$. Em seguida, os pedaços foram enxaguados com água clorada $\left(0,2\right.$ g. $\left.\mathrm{L}^{-1}\right)$ para eliminar o suco celular extravasado. A água foi drenada por 2 a 3 minutos sobre peneiras.

\section{C) Preparo e aplicação de revestimentos}

No revestimento foram utilizados glicerol (Quimex, Brasil) e quitosana (grau de desacetilação em torno de $89 \%$, e massa molecular entre 150 e $170 \mathrm{kDa}$ ) sendo que esta foi dissolvida em solução contendo um pouco de ácido cítrico.
As soluções foram preparadas por dissolução lenta da quitosana em água destilada, sob agitação, até completa dissolução, seguindo de aquecimento a $60^{\circ} \mathrm{C}$, por 20 minutos, e resfriamento até a temperatura ambiente, para após serem adicionadas do plastificante glicerol, argila organofílica Montmorillonita e óleo essencial de cravo conforme o tratamento que iria ser utilizado.

Obteve-se 4 tratamentos: T1-Controle (melão sem revestimento); T2-quitosana (1\%) + glicerol $(0,5 \%)$; T3-quitosana $(1 \%)+$ glicerol $(0,5 \%)+$ montmorillonita (MMT) $(0,3 \%) ;$ T4-quitosana (1\%) + glicerol $(0,5 \%)+\operatorname{MMT}(0,3 \%)+$ óleo essencial de cravo (OEC) $(0,5 \%)$.

Os pedaços de melão foram totalmente submersos nas soluções por 3 minuto e, em seguida, drenados, os melões minimamente processados foram armazenados em embalagem PET-Polietileno Tereftalato, com tampa (SANPACK), com tampa (SANPACK), cujas medidas externas são de 15,5 x 13,2 x 5,5 cm, padronizando o número de pedaços por embalagem (8 pedaços) por um período de 7 dias a $4 \pm 1^{\circ} \mathrm{C}$.

As análises físicas, físico-químicas e microbiológicas foram realizadas em triplicata no dia do processamento das amostras (dia 0) e após 1, 3, 5 e 7 dias de armazenamento.

D) Análises físicas e físico-químicas

\section{Análise de pH}

Para medida do $\mathrm{pH}, 20 \mathrm{~g}$ das amostras foram trituradas em $100 \mathrm{~mL}$ de água destilada, em seguida realizou-se a medição utilizando um pHmetro (Marconi PA 200). A análise foi realizada segundo o método descrito por AOAC. ${ }^{14}$

\section{Teor de sólidos solúveis totais ( ${ }^{\circ} \mathrm{Brix}$ )}

Os teores de sólidos solúveis totais foram determinados a partir do extrato líquido obtido após a trituração da amostra. Utilizou-se um refratômetro de bancada (marca Abbe, UK), sem controle automático de temperatura. Os resultados foram expressos em ${ }^{\circ}$ Brix. ${ }^{14}$

\section{Análise de acidez}

A acidez titulável foi determinada e calculada como o volume em $\mathrm{mL}$ de $\mathrm{NaOH} 0,1$ mol.L ${ }^{-1}$, requerido para titular $10 \mathrm{~mL}$ de amostra diluída e homogeneizada em $100 \mathrm{~mL}$ de água. Os resultados foram expressos em porcentagem de ácido cítrico. ${ }^{14}$ 


\section{E) Análises microbiológicas}

Para as análises microbiológicas, adicionouse $225 \mathrm{~mL}$ de água peptonada $0,1 \%(\mathrm{p} / \mathrm{v})$ estéril a $25 \mathrm{~g}$ de amostra. Em seguida foram homogeneizadas em Blenders por 60 segundos e feitas sucessivas diluições em água peptonada $0,1 \%(p / v)$ estéril.

As diluições das amostras foram selecionadas, baseando-se na contagem de microorganismos esperada para cada amostra. Os testes microbiológicos realizados foram bolores e leveduras, Escherichia coli e Salmonella spp., seguindo a metodologia descrita na $\mathrm{Apha}^{15}$ e Brasil. ${ }^{16}$

\section{F) Análise sensorial}

Para a análise sensorial foram utilizados 12 julgadores treinados. Foram avaliados para cada tratamento atributos, sendo textura, cor, aroma e avaliação global (que nada mais é do que a avaliação de um todo do produto, onde se analisa todas as características avaliadas juntas) durante os 7 dias de armazenamento a $4^{\circ} \mathrm{C}$. Foi estabelecida uma escala que variou de 5 a 1 , onde 5 significava amostra de ótima qualidade (fresca, aromática e sem escurecimento); 4 significava amostra de boa qualidade (fresca e com leve escurecimento); 3 significava regular (pouco fresca, aroma menos acentuado e moderado escurecimentos); 2 significava ruim (a amostra não estava mais fresca e com elevado escurecimento); 1 a amostra estava péssima (sem frescor e aroma e com elevado grau de escurecimento e presença de bolores).

\section{G) Análise Estatística}

As análises foram realizadas em triplicata e os resultados foram apresentados pela média. Os resultados obtidos foram avaliados estatisticamente através de análise de variância (ANOVA) seguida do teste de Tukey a $5 \%$ de significância, utilizando o programa Statistica 6.0.

\section{RESULTADOS E DISCUSSÃO}

Os teores de sólidos solúveis totais ( $\left.{ }^{\circ} \mathrm{Brix}\right), \mathrm{pH}$, acidez titulável de melões minimamente processados obtidos por diferentes tratamentos são apresentados na Tabela 1.

Podemos observar na Tabela 1 que houve um aumento mais acentuado nos valores de $\mathrm{pH}$ nos últimos dias de avaliação, sendo que em todos os tratamentos avaliados entre o quinto e o sétimo dia não apresentaram diferença significativa entre eles.

Até o terceiro dia de armazenamento foram observadas diferenças entre alguns tratamentos para os valores de $\mathrm{pH}$. Segundo Pizarro, ${ }^{17}$ isso pode estar relacionado com importantes deteriorações bioquímicas (fermentação lática) podendo ser sinais de contaminações microbianas.

Em relação aos valores de acidez titulável encontrados para o melão minimamente processado pode-se observar que ouve uma diminuição dos valores, sendo que o tratamento T3 foi o que apresentou menor diminuição durante os 7 dias de análises diferindo significativamente dos tratamentos T1 e T2.

Na maioria dos frutos, é comum observar redução de acidez durante o amadurecimento, devido ao uso dos ácidos orgânicos como fonte de energia. ${ }^{18}$ De acordo com Russo, Daiuto e Vieites ${ }^{19}$ no amadurecimento, os ácidos orgânicos sofrem oxidação no ciclo de Krebs, e, consequentemente, ocorre diminuição nos seus teores. Essa diminuição geralmente é devida ao consumo dos ácidos ou conversão em açúcares, pois os mesmos são considerados reserva de energia e são utilizados na atividade metabólica do processo de amadurecimento.

Araújo $^{20}$ estudando melão 'Orange Flesh' minimamente processado armazenado em atmosfera modificada ativa a $5 \pm 1^{\circ} \mathrm{C}$ e $85 \pm 5 \%$ de umidade relativa, encontrou teores de acidez relativamente estáveis e com tendência à redução também como neste estudo. Lamikanra et al. ${ }^{21}$ observaram oscilações no teor de acidez titulável em melões Cantaloupe minimamente processados. Os mesmos autores afirmam que, com o amadurecimento, as frutas perdem rapidamente a acidez, mas, em alguns casos, há um pequeno aumento nos valores com o avanço da maturação devido as características naturais da fruta. A acidez pode ser utilizada, em conjunto com a doçura, como ponto de referência do grau de maturação. Os valores de acidez também diminuíram em todos os tratamentos avaliados, sendo que o tratamento controle apresentou menor diminuição da acidez (47\%) em 7 dias de armazenamento, valor inferior quando comparado com a amostra controle que obteve $70 \%$ de diminuição dos valores de acidez neste período. 
Tabela 1. Resultados de pH, acidez titulável e sólidos solúveis ('Brix) de melões minimamente processados tratados com diferentes coberturas à base de quitosana e armazenadas a $4 \pm 1^{\circ} \mathrm{C}$ durante 7 dias.

Table 1. $p H$ results, titratable acidity and soluble solids (Brix) of minimally processed melons treated with different chitosan based coatings and stored at $4 \pm 1^{\circ} \mathrm{C}$ for 7 days.

\begin{tabular}{|c|c|c|c|c|c|}
\hline \multirow{2}{*}{ Análises } & \multirow{2}{*}{ Dias } & \multicolumn{4}{|c|}{ Tratamentos } \\
\hline & & T1 & T2 & T3 & T4 \\
\hline \multirow{5}{*}{$\mathrm{pH}$} & 0 & $5,18 \pm 0,04^{\mathrm{bBC}}$ & $5,94 \pm 0,04^{\mathrm{CAB}}$ & $4,77 \pm 0,58^{\mathrm{bc}}$ & $6,04 \pm 0,04^{\mathrm{bA}}$ \\
\hline & 1 & $5,24 \pm 0,29^{b c}$ & $6,76 \pm 0,12^{\mathrm{bA}}$ & $5,25 \pm 0,19^{b c}$ & $6,11 \pm 0,09^{\mathrm{bB}}$ \\
\hline & 3 & $4,74 \pm 0,02^{\mathrm{CB}}$ & $5,73 \pm 0,06^{\mathrm{cA}}$ & $4,83 \pm 0,18^{\mathrm{bB}}$ & $6,01 \pm 0,23^{\mathrm{bA}}$ \\
\hline & 5 & $7,03 \pm 0,06^{\mathrm{aA}}$ & $7,20 \pm 0,00^{\mathrm{aA}}$ & $7,03 \pm 0,06^{\mathrm{aA}}$ & $7,13 \pm 0,15^{\mathrm{aA}}$ \\
\hline & 7 & $7,13 \pm 0,15^{\mathrm{aA}}$ & $7,30 \pm 0,17^{\mathrm{aA}}$ & $7,07 \pm 0,12^{\mathrm{aA}}$ & $7,30 \pm 0,17^{\mathrm{aA}}$ \\
\hline \multirow{5}{*}{$\begin{array}{l}\text { Acidez } \\
\text { Titulável }\end{array}$} & 0 & $1,57 \pm 0,81^{\mathrm{aA}}$ & $0,53 \pm 0,10^{\mathrm{aB}}$ & $1,83 \pm 0,18^{\mathrm{aA}}$ & $1,00 \pm 0,20^{\mathrm{aA}}$ \\
\hline & 1 & $1,47 \pm 0,12^{\mathrm{aA}}$ & $0,40 \pm 0,06^{\mathrm{ac}}$ & $1,20 \pm 0,40^{\mathrm{abA}}$ & $0,57 \pm 0,06^{\mathrm{bB}}$ \\
\hline & 3 & $1,40 \pm 0,40^{\mathrm{aA}}$ & $0,53 \pm 0,12^{\mathrm{aB}}$ & $1,37 \pm 0,21^{\mathrm{bA}}$ & $0,55 \pm 0,05^{\mathrm{bB}}$ \\
\hline & 5 & $0,47 \pm 0,06^{\mathrm{bA}}$ & $0,23 \pm 0,06^{\mathrm{bB}}$ & $0,53 \pm 0,06^{\mathrm{cA}}$ & $0,40 \pm 0,00^{\mathrm{bA}}$ \\
\hline & 7 & $0,47 \pm 0,06^{\mathrm{bB}}$ & $0,25 \pm 0,06^{\mathrm{bB}}$ & $0,63 \pm 0,04^{\mathrm{cA}}$ & $0,53 \pm 0,06^{\mathrm{bAB}}$ \\
\hline \multirow{5}{*}{$\begin{array}{c}\text { Sólidos } \\
\text { Solúveis } \\
\text { totais ( }{ }^{\circ} \text { Brix) }\end{array}$} & 0 & $6,40 \pm 0,66^{\mathrm{cB}}$ & $6,20 \pm 1,31^{\mathrm{bB}}$ & $9,40 \pm 0,53^{\mathrm{bA}}$ & $8,80 \pm 0,72^{\mathrm{cA}}$ \\
\hline & 1 & $6,77 \pm 0,87^{\mathrm{cB}}$ & $11,00 \pm 1,73^{\mathrm{aA}}$ & $9,43 \pm 0,51^{\mathrm{bAB}}$ & $9,43 \pm 0,40^{\mathrm{bAB}}$ \\
\hline & 3 & $8,70 \pm 0,26^{\mathrm{bB}}$ & $12,13 \pm 0,99^{a A}$ & $11,83 \pm 0,76^{\mathrm{aA}}$ & $10,33 \pm 0,58^{\mathrm{bAB}}$ \\
\hline & 5 & $11,77 \pm 0,25^{\mathrm{aAB}}$ & $12,07 \pm 0,06^{\mathrm{aA}}$ & $11,80 \pm 0,20^{\mathrm{aAB}}$ & $11,47 \pm 0,06^{\mathrm{aB}}$ \\
\hline & 7 & $11,83 \pm 0,29^{\mathrm{aAB}}$ & $11,37 \pm 0,40^{\mathrm{aB}}$ & $12,23 \pm 0,21^{\mathrm{aA}}$ & $12,03 \pm 0,06^{\mathrm{aAB}}$ \\
\hline
\end{tabular}

Médias seguidas de mesma letra minúscula na coluna e maiúscula na linha não diferem entre si, pelo Teste de Tukey $(P<0,05)$. (T1) controle; (T2) quitosana $1 \%(\mathrm{~m} / \mathrm{v})$, glicerol $0,5 \%$ $(\mathrm{v} / \mathrm{v})$; (T3) quitosana $1 \%(\mathrm{~m} / \mathrm{v})$, glicerol $0,5 \%(\mathrm{v} / \mathrm{v})$, MMT $0,3 \%(\mathrm{~m} / \mathrm{v}) ;(\mathrm{T} 4)$ quitosana $1 \%$ $(\mathrm{m} / \mathrm{v})$, glicerol 0,5\% (v/v), MMT 0,3\% (m/v), OEC 0,5\% (m/v).

Means followed by the same letter in the column and capital in line do not differ by Tukey test $(P<0,05)$. (T1) control; (T2) chitosan 1\% (w/v), glycerol 0,5\% (v/v); (T3) chitosan 1\% (w/v), glycerol 0,5\% (v/v), MMT 0,3\% (w/v); (T4) chitosan 1\% (w/v), glycerol 0,5\% (v/v), MMT 0,3\% $(w / v), O E C 0,5 \%(w / v)$.

Os valores de sólidos solúveis ( $\left.{ }^{\circ} \mathrm{Brix}\right)$ encontrados no presente estudo aumentaram entre o primeiro e o último dia de armazenamento

A amostra controle foi a que apresentou maior aumento do teor de sólidos solúveis durante os 7 dias de armazenamento (45,9\%) e a amostra que continha quitosana, glicerol e montmorillonita (T3) apresentou menor aumento dos sólidos solúveis durante o período de estudo $(23,13 \%)$ seguida do tratamento T4 que continha quitosana, glicerol, montmorillonita e óleo essencial de cravo (26,84\%). Somente o uso de quitosana (T2) não impediu um aumento elevado do teor de sólidos solúveis ficando o seu valor em porcentagem $(45,47 \%)$ quase semelhante ao do tratamento controle.

Estes resultados mostram que os tratamentos com a montmorillonita e óleo essencial de cravo impediram de certa forma a senescência da fruta. $O$ aumento observado nos sólidos solúveis totais em alguns tratamentos do quinto dia em diante pode estar relacionado ao acúmulo de açúcares pela perda da umidade. $^{22}$ A perda de massa que demostra a perda de umidade não foi medida neste estudo, porém foi observada visualmente. Já no tratamento $\mathrm{T} 2$ houve redução do teor de sólidos solúveis, este comportamento pode estar associado ao consumo de açúcares, devido ao maior 
metabolismo respiratório da fruta, e ao crescimento de micro-organismos ${ }^{23}$, sendo que o aumento de bolores e leveduras foi observado durante as análises microbiológicas principalmente para este tratamento e para o tratamento controle.

Não foi detectada a presença de Escherichia coli $\left(<10^{2}\right.$ UFC. $\left.g^{-1}\right)$, assim como de Salmonella (ausência em 25g) para todos os tratamentos avaliados de melões minimamente processados, confirmando a eficiência dos cuidados higiênicos e da ação do cloro orgânico na desinfecção das amostras. No Brasil, ainda não existe legislação específica para frutas e hortaliças minimamente processadas com os limites de contagens tolerados. Entretanto, existe legislação para frutas frescas, in natura, preparadas (descascadas ou selecionadas ou fracionadas) sanitizadas, refrigeradas ou congeladas, que estipula valores máximos de coliformes termotolerantes de $5 \times 10^{2}$ UFC. $^{-1}$ e ausência de Salmonella em $25 \mathrm{~g}$ de amostra. ${ }^{16}$

Na Tabela 2 são apresentados os valores de crescimento de bolores e leveduras (UFC. ${ }^{-1}$ ) encontrados para os diferentes tratamentos avaliados utilizados em melão minimamente processados durante 7 dias de armazenamento.

Tabela 2. Crescimento de bolores e leveduras (UFC ${ }^{-1}$ ) em melão minimamente processado armazenados em $4^{\circ} \mathrm{C}$ por 7 dias

Table 2. Growth of molds and yeasts (CFU. $\mathrm{g}^{-1}$ ) into minimally processed melon stored at $4^{\circ} \mathrm{C}$ for 7 days

\begin{tabular}{ccccc}
\hline \multirow{2}{*}{ Dias } & \multicolumn{4}{c}{ Tratamentos } \\
\cline { 2 - 5 } & $\mathrm{T} 1$ & $\mathrm{~T} 2$ & $\mathrm{~T} 3$ & $\mathrm{~T} 4$ \\
\hline 0 & $0,0 \pm 0,0^{\mathrm{dA}}$ & $0,0 \pm 0,0^{\mathrm{CA}}$ & $0,0 \pm 0,0^{\mathrm{bA}}$ & $0,0 \pm 0,0^{\mathrm{cA}}$ \\
1 & $0,0 \pm 0,0^{\mathrm{dA}}$ & $0 \pm 0,0^{\mathrm{cA}}$ & $0,0 \pm 0,0^{\mathrm{bA}}$ & $0,0 \pm 0,0^{\mathrm{cA}}$ \\
3 & $0,7 \pm 0,03^{\mathrm{cA}}$ & $0,12 \pm 0,15^{\mathrm{bB}}$ & $0,0 \pm 0,0^{\mathrm{bC}}$ & $0,0 \pm 0,0^{\mathrm{cC}}$ \\
5 & $1,0 \pm 0,07^{\mathrm{bA}}$ & $0,25 \pm 0,02^{\mathrm{bB}}$ & $0,0 \pm 0,0^{\mathrm{bD}}$ & $0,15 \pm 0,0^{\mathrm{bC}}$ \\
7 & $2,22 \pm 0,20^{\mathrm{aA}}$ & $1,22 \pm 0,07^{\mathrm{aB}}$ & $0,40 \pm 0,25^{\mathrm{aC}}$ & $0,60 \pm 0,07^{\mathrm{aC}}$ \\
\hline
\end{tabular}

Médias seguidas de mesma letra minúscula na coluna e maiúscula na linha não diferem entre si, pelo Teste de Tukey ( $P<0,05)$. (T1) controle; (T2) quitosana $1 \%(\mathrm{~m} / \mathrm{v})$, glicerol $0,5 \%$ $(\mathrm{v} / \mathrm{v})$; (T3) quitosana $1 \%(\mathrm{~m} / \mathrm{v})$, glicerol $0,5 \%(\mathrm{v} / \mathrm{v})$, MMT 0,3\% (m/v); (T4) quitosana $1 \%$ $(\mathrm{m} / \mathrm{v})$, glicerol $0,5 \%(\mathrm{v} / \mathrm{v})$, MMT $0,3 \%(\mathrm{~m} / \mathrm{v})$, OEC $0,5 \%(\mathrm{p} / \mathrm{v})$.

Averages followed by the same letter in the column and capital in line do not differ by Tukey test $(P<0,05)$. (T1) control; (T2) chitosan 1\% (w/v), glycerol 0,5\% (v/v); (T3) chitosan $1 \%(w / v)$, glycerol 0,5\% (v/v), MMT 0,3\% (w/v); (T4) chitosan 1\% (w/v), glycerol 0,5\% (v/v), MMT 0,3\% $(w / v), O E C 0,5 \%(w / v)$.

O crescimento de bolores e leveduras foi baixo em todos os tratamentos avaliados neste trabalho, sendo que o tratamento T1 (controle) foi o tratamento que apresentou maior crescimento, sendo que o aparecimento de bolores e leveduras nas placas foi observado apenas no terceiro dia de armazenamento para o tratamento T1 e T2. Já para o tratamento T4 o aparecimento de bolores e leveduras foi observado a partir do quinto dia e para o tratamento T3 apenas nos sétimo e último dia de estudo para o melão minimamente processado. Damasceno et al. ${ }^{24}$ também encontraram um crescimento de bolores e leveduras que apesar de constante, somente apresentou aumento significativo em relação ao dia zero no décimo dia de armazenamento.

No final dos dias de armazenamento se observou um aumento da concentração de bolores e leveduras. Esse aumento observado fez com que os tratamentos $\mathrm{T} 1$ e T2 apresentassem diferença significativa entre eles e não foi observada diferença significativa entre o T3 e T4 demonstrando que o uso de montmorillonita (T3) e óleo essencial de cravo (T4) foram eficientes para o retardamento do aparecimento de bolores e leveduras em melão minimamente processado. Lima et al. $^{25}$ 
observaram que bolores e leveduras que cresceram no tratamento controle de melão (Orange flesh) minimamente processado somente apresentou crescimento no $4^{\circ}$ dia de armazenamento. No $6^{\circ}$ dia, os frutos sob as concentrações de $1 \%$ e $2 \%$ de ácido ascórbico apresentaram pequena população em comparação aos frutos do tratamento controle; no $8^{\circ}$ dia, o tratamento controle e a concentração de $1 \%$ de ácido ascórbico apresentaram bolores e leveduras, no entanto, na concentração de $1 \%$ de ácido ascórbico estas foram muito baixas $\left(0,5 \times 10^{-1}\right)$.

A Tabela 3 apresenta os valores de análise sensorial encontrados para o melão minimamente processado armazenado em $4^{\circ} \mathrm{C}$ por um período de 7 dias.

Tabela 3. Avaliação dos atributos sensoriais textura, cor, aroma e avaliação global de melões minimamente processados armazenados a $4^{\circ} \mathrm{C}$ por 7 dias

Table 3. Sensory Evaluation of attributes texture, color, flavor and overall evaluation of minimally processed melons stored at $4^{\circ} \mathrm{C}$ for 7 days

\begin{tabular}{|c|c|c|c|c|c|c|}
\hline \multirow{2}{*}{$\begin{array}{l}\text { Atributos } \\
\text { sensoriais }\end{array}$} & \multirow{2}{*}{ Tratamentos } & \multicolumn{5}{|c|}{ Tempo (dias) } \\
\hline & & 0 & 1 & 3 & 5 & 7 \\
\hline \multirow{4}{*}{ Textura } & $\mathrm{T} 1$ & $5,0 \pm 0,1^{\mathrm{aA}}$ & $4,8 \pm 0,2^{\mathrm{aA}}$ & $4,8 \pm 0,1^{\mathrm{aA}}$ & $4,2 \pm 0,1^{\mathrm{cB}}$ & $3,1 \pm 0,1^{c C}$ \\
\hline & $\mathrm{T} 2$ & $5,0 \pm 0,1^{\mathrm{aA}}$ & $4,9 \pm 0,1^{\mathrm{aA}}$ & $4,8 \pm 0,1^{\mathrm{aA}}$ & $4,5 \pm 0,1^{\mathrm{bB}}$ & $3,7 \pm 0,1^{b c}$ \\
\hline & T3 & $5,0 \pm 0,1^{\mathrm{aA}}$ & $5,0 \pm 0,1^{\mathrm{aA}}$ & $4,9 \pm 0,1^{\mathrm{aAB}}$ & $4,7 \pm 0,1^{\mathrm{aB}}$ & $4,3 \pm 0,1^{\mathrm{aC}}$ \\
\hline & $\mathrm{T} 4$ & $5,0 \pm 0,1^{\mathrm{aA}}$ & $5,0 \pm 0,1^{\mathrm{aA}}$ & $4,9 \pm 0,1^{\mathrm{aA}}$ & $4,8 \pm 0,1^{\mathrm{aA}}$ & $4,5 \pm 0,1^{\mathrm{aB}}$ \\
\hline \multirow{4}{*}{ Cor } & $\mathrm{T} 1$ & $5,0 \pm 0,1^{\mathrm{aA}}$ & $5,0 \pm 0,1^{\mathrm{aA}}$ & $4,4 \pm 0,1^{\mathrm{bB}}$ & $4,1 \pm 0,1^{b c}$ & $3,0 \pm 0,1^{C D}$ \\
\hline & $\mathrm{T} 2$ & $5,0 \pm 0,1^{\mathrm{aA}}$ & $5,0 \pm 0,1^{\mathrm{aA}}$ & $4,8 \pm 0,1^{\mathrm{aA}}$ & $4,6 \pm 0,1^{\mathrm{aB}}$ & $3,4 \pm 0,1^{b c}$ \\
\hline & T3 & $5,0 \pm 0,1^{\mathrm{aA}}$ & $5,0 \pm 0,1^{\mathrm{aA}}$ & $4,9 \pm 0,1^{\mathrm{aA}}$ & $4,6 \pm 0,1^{\mathrm{aB}}$ & $4,2 \pm 0,1^{\mathrm{ac}}$ \\
\hline & $\mathrm{T} 4$ & $5,0 \pm 0,1^{\mathrm{aA}}$ & $5,0 \pm 0,1^{\mathrm{aA}}$ & $4,9 \pm 0,1^{\mathrm{aAB}}$ & $4,7 \pm 0,1^{\mathrm{aB}}$ & $4,0 \pm 0,1^{\mathrm{aC}}$ \\
\hline \multirow{4}{*}{ Aroma } & $\mathrm{T} 1$ & $5,0 \pm 0,1^{\mathrm{aA}}$ & $5,0 \pm 0,1^{\mathrm{aA}}$ & $4,2 \pm 0,1^{\mathrm{bB}}$ & $4,1 \pm 0,1^{\mathrm{bB}}$ & $4,1 \pm 0,1^{b B}$ \\
\hline & $\mathrm{T} 2$ & $5,0 \pm 0,1^{\mathrm{aA}}$ & $5,0 \pm 0,1^{\mathrm{aA}}$ & $4,9 \pm 0,1^{\mathrm{aA}}$ & $4,5 \pm 0,1^{\mathrm{aB}}$ & $3,3 \pm 0,1^{c c}$ \\
\hline & T3 & $5,0 \pm 0,1^{\mathrm{aA}}$ & $5,0 \pm 0,1^{\mathrm{aA}}$ & $4,8 \pm 0,1^{\mathrm{aA}}$ & $4,6 \pm 0,1^{\mathrm{aB}}$ & $4,3 \pm 0,1^{\mathrm{aC}}$ \\
\hline & $\mathrm{T} 4$ & $5,0 \pm 0,1^{\mathrm{aA}}$ & $5,0 \pm 0,1^{\mathrm{aA}}$ & $4,9 \pm 0,1^{\mathrm{aA}}$ & $4,7 \pm 0,1^{\mathrm{aB}}$ & $4,5 \pm 0,1^{\mathrm{ac}}$ \\
\hline \multirow{4}{*}{$\begin{array}{l}\text { Avaliação } \\
\text { global }\end{array}$} & $\mathrm{T} 1$ & $5,0 \pm 0,1^{\mathrm{aA}}$ & $5,0 \pm 0,1^{\mathrm{aA}}$ & $4,5 \pm 0,1^{\mathrm{bB}}$ & $4,1 \pm 0,1^{b c}$ & $4,0 \pm 0,1^{b c}$ \\
\hline & $\mathrm{T} 2$ & $5,0 \pm 0,1^{\mathrm{aA}}$ & $5,0 \pm 0,1^{\mathrm{aA}}$ & $4,9 \pm 0,1^{\mathrm{aA}}$ & $4,6 \pm 0,1^{\mathrm{aB}}$ & $4,4 \pm 0,1^{\mathrm{aB}}$ \\
\hline & T3 & $5,0 \pm 0,1^{\mathrm{aA}}$ & $5,0 \pm 0,1^{\mathrm{aA}}$ & $4,9 \pm 0,1^{\mathrm{aAB}}$ & $4,7 \pm 0,1^{\mathrm{aBC}}$ & $4,5 \pm 0,1^{\mathrm{ac}}$ \\
\hline & $\mathrm{T} 4$ & $5,0 \pm 0,1^{\mathrm{aA}}$ & $5,0 \pm 0,1^{\mathrm{aA}}$ & $4,9 \pm 0,1^{\mathrm{aAB}}$ & $4,7 \pm 0,1^{\mathrm{aBC}}$ & $4,5 \pm 0,1^{\mathrm{ac}}$ \\
\hline
\end{tabular}

Médias seguidas de mesma letra minúscula na coluna e maiúscula na linha não diferem entre si, pelo Teste de Tukey $(\mathrm{P}<0,05)$. (T1) controle; (T2) quitosana $1 \%(\mathrm{~m} / \mathrm{v})$, glicerol $0,5 \%$ $(\mathrm{v} / \mathrm{v})$; (T3) quitosana $1 \%(\mathrm{~m} / \mathrm{v})$, glicerol $0,5 \%(\mathrm{v} / \mathrm{v})$, MMT $0,3 \%(\mathrm{~m} / \mathrm{v})$; (T4) quitosana $1 \%$ $(\mathrm{m} / \mathrm{v})$, glicerol 0,5\% (v/v), MMT 0,3\% (m/v), OEC 0,5\% (p/v).

Average followed by the same letter in the column and capital in line do not differ by Tukey test $(P<0,05)$. (T1) control; (T2) chitosan 1\% (w/v), glycerol 0,5\% (v/v); (T3) chitosan $1 \%$ $(w / v)$, glycerol 0,5\% (v/v), MMT0,3\% (w/v); (T4) chitosan 1\% (w/v), glycerol 0,5\% (v/v), MMT $0,3 \%(w / v)$, OEC $0,5 \%(w / v)$. 
Podemos observar na Tabela 3 que todos os atributos avaliados para todos os tratamentos estudados não apresentaram diferença significativa nos dias 0 e 1 de armazenamento. Houve em todos os atributos avaliados a diminuição da aceitabilidade das amostras pelos julgadores sendo que o tratamento controle foi o que apresentou a maior diminuição dos valores e o mesmo tratamento apresentou diferença significativa entre o primeiro e o último dia de armazenamento em relação a todos os atributos avaliados. Essa diminuição foi verificada nos outros tratamentos também, porém com menor intensidade na diminuição dos valores, principalmente nos tratamentos T3 e T4.

Os tratamentos que continham quitosana não apresentaram diferença significativa até o quinto dia de armazenamento para todos os atributos avaliados. Já a amostra controle (T1) somente apresentou esse mesmo comportamento quando o atributo avaliado foi textura. As perdas sensoriais foram menores estatisticamente quando se aplicou quitosana, quitosana com montmorillonita e quitosana com óleo essencial de cravo.

Trabalho realizado por Pizarro et al. ${ }^{17}$ encontraram para valores de aroma notas mais baixas em comparação com a amostra controle durante o armazenamento quando trabalhou com diferentes embalagens plásticas. Esses resultados não estão de acordo com o presente trabalho, pois neste estudo foram encontrados valores maiores no último dia de armazenamento para os outros tratamentos em relação a amostra controle.

Trabalho realizado por Arruda et al. ${ }^{26}$ verificaram que a qualidade do melão rendilhado minimamente processado manteve boa qualidade sensorial por 6 dias quando armazenado a $3^{\circ} \mathrm{C}$. Estes resultados concordam com 0 presente estudo, pois em 7 dias de armazenamento os melões minimamente processados apresentaram características sensoriais boas, não apresentando alterações profundas em relação a aparência do produto.

\section{CONCLUSÃO}

O presente estudo foi que o Método do Índice da Qualidade do Mapará com 26 pontos de demérito e 13 atributos de qualidade foi eficaz para avaliar o frescor e estimar a vida útil da espécie.

\section{CONTRIBUIÇÃO DOS AUTORES}

Os autores RCC, GFAS, DMS, SP e WRCV participaram na condução do experimento, análise dos dados e elaboração do artigo científico.

\section{FINANCIAMENTO}

Os autores reportam que não houve suporte e auxílio financeiro durante o desenvolvimento da pesquisa.

\section{CONFLITO DE INTERESSE}

Os autores declaram que não há conflito de interesse.

\section{COMO CITAR ESSE DOCUMENTO}

\section{ABNT}

CHEVALIER, Raquel Costa et al. Utilização de revestimento comestivel a base de quitosana para aumentar a vida útil de melão minimamente processado. Journal of bioenergy and food science, v.3, n.3, p.130-138, 2016. DOI:10.18067/jbfs.v3i3.101

\section{APA}

Chevalier, R., da Silva, G., da Silva, D., Pizato, S \& Cortez-Vega, W. (2016). Utilização de revestimento comestível a base de quitosana para aumentar a vida útil de melão minimamente processado. Journal Of Bioenergy And Food Science, 3(3) 130138. DOI:10.18067/jbfs.v3i3.101

\section{REFERÊNCIAS BIBLIOGRÁFICAS}

1. GUNES, G.; LEE, C. Y. Color of Minimally Processed Potatoes as Affected by Modified Atmosphere Packaging and Antibrowning Agents. Ciência e Tecnologia de Alimentos, v.25, p.651-658, 1997.

2. LIMA L. C. 2005. Qualidade do melão 'Orange Flesh' minimamente processado e submetido a diferentes métodos de conservação. Tese de Doutorado em Agronomia (Horticultura) - Faculdade de Ciências Agronômicas, Universidade Estadual de São Paulo, 130f, Botucatu-SP, 2005.

3. CHIUMARELLI, M., FERRARI, C. C., SARANTÓPOULOS, C. I. G. L. AND HUBINGER, M. D. Fresh cut 'Tommy Atkins' mango pre-treated with citric acid and coated with cassava (Manihot esculenta Crantz) starch or sodium alginate. Innovative Food Science \& Emerging Technology, v.12: p.381-387, 2011. DOI 10.1016/j.ifset.2011.02.006

4. PIZATO, S.; BORgES, J. A.; MARTINS, V. G.; PRENTICE, C.; CORTEZ-VEGA, W.R. Whitemouth croaker (Micropogonias furnieri) protein isolate and organoclay nanocomposite coatings on shelf life and quality of fresh-cut pear. International Food Research Journal, v.22: p.163-170, 2015 
5. VANKERSCHAVER, K.; WILLOCX, F.; SMOUT. C.; HENDRICKX, M.; TOBBACK, P. Modeling and prediction of visual shelf life of minimally processed endive. Journal of Food Science, v.61: p.1094-1098, 1996. DOI 10.1111/j.13652621.1996.tb10938.x

6. VILAS BOAS, B. M.; PRADO, M. E. T.; VILAS BOAS, E. V. DE B.; NUNES, E. E.; ARAÚJO, F. M. M. C.; CHITARRA, E. B. Qualidade pós-colheita de melão 'Orange Flesh' minimamente processado armazenado sob refrigeração e atmosfera modificada. Revista Brasileira de Fruticultura, v. 26, p. 424-427, 2004. DOI 10.1590/S010029452004000300013

7. ROJAS-GRAU, M. A., SOLIVA-FORTUNY, R. C. AND MARTÍN- BELLOSO, O. Edible coatings to incorporate active ingredients to fresh-cut fruits: a review. Trends in Food Science and Technology, v.20: p.438-447, 2009. DOI 10.1016/j.tifs.2009.05.002

8. RICO, D., MARTIN-DIANA, A. B. AND BARAT, J. M. Extending and measuring the quality of fresh-cut fruit and vegetables: a review. Trends in Food Science and Technology, v.18: p. 373-386, 2007

9. SOARES, N. F. F.; GERALDINE, R. M. "Embalagens". In: MORETTI, C. L. Manual de processamento mínimo de frutas e hortaliças. Pesquisa Agropecuária Brasileira, cap. 4, p. 153-172, 2007.

10. CAMPANA-FILHO, S.P.; DESBRIÈRES, J. Chitin, chitosan and derivatives. In Natural polymers and agrofibers composites. São Carlos: Embrapa Instrumentação Agropecuária, p.41-71, 2000.

11. PANDEY, J. K.; KUMAR, A. P.; MISRA, M.; MOHANTY, A. K.; DRZAL, L. T.; SINGH, R. P. Recent advances in biodegradable nanocomposites. Journal of Nanoscience and Nanotechnology, v.5, n.4, p.497-526, 2005.

12. CORTEZ-VEGA, W. R. Desenvolvimento de filmes nanocompósitos de isolado protéico de corvina (Micropogonias furnieri) e argila organofílica. 156f. Tese (Doutorado em Engenharia e Ciência de Alimentos) Universidade Federal do Rio Grande-FURG, 2011.

13. BAKKALI, F.; AVERBECK, S.; AVERBACK, D.; WAOMAR, M.. Biological effects of essential oils - A review. Food Chemistry Toxicology, v. 46, p.446-475, 2008. DOI 10.1016/j.fct.2007.09.106

14. ASSOCIATION OF OFFICIAL ANALYTICAL CHEMISTS AOAC. Official methods of analysis. $16^{\text {th }}$ ed. Washington, D.C, 2000.

15. AMERICAN PUBLIC HEALTH ASSOCIATION -APHA. Compendium of methods for the microbiological examination of foods. Washington, D.C, 2001.676 p.

16. BRASIL. Ministério da Saúde. Resolução RD C $n^{\circ} 12$, de 02 de janeiro de 2001. Aprova o Regulamento Técnico sobre padrões microbiológicos para alimentos. Diário Oficial [da] República Federativa do Brasil, Brasília, DF, 10 jan. 2001. Seção 1, p. 46-53, 2001.

17. PIZARRO, C. A. C.; BENEDETTI, B. C.; HAJ-ISA, N. M. Avaliação de melão minimamente processado armazenado em diferentes temperaturas e embalagens. Ciência e Tecnologia de Alimentos, v.26, p.246-52, 2006. DOI 10.1590/S0101-20612006000200003

18. CHITARRA, M. I. F, CHITARRA, A. B. Pós-colheita de frutos e hortaliças: Fisiologia e Manuseio. 2.ed. Lavras: Editora UFLA, 2005.

19. RUSSO, V. C.; DAIUTO, E. R.; VIEITES, R. L. Melão amarelo (CAC) minimamente processado submetido a diferentes cortes e concentrações de cloreto de cálcio armazenado em atmosfera modificada passiva. Journal Semina: Ciências Agrárias, v. 33: p. 227-236, 2012. DOI 10.5433/1679-0359.2012v33n1p227

20. ARAÚJO, F. M. M. C. Qualidade de melão tipo Orange Flesh minimamente processado, armazenado sob atmosfera modificada ativa. Tese de Doutorado em Ciência dos Alimentos, Universidade Federal de Lavras, Lavras-MG, 2003.

21. LAMIKANRA, O.; CHEN, J. C.; BANKS, D.; HUNTER, P. $A$. Biochemical and microbiological changes during the storage of minimally processed cantaloupe. Journal of Agriculture and Food Chemistry, Easton, v.48, n.12 p.5955-5961, 2000. DOI 10.1021/jf0000732

22. COSTA, A. F. S.; BALBINO, J. M. S. Características da fruta para exportação e normas de qualidade. Pesquisa Agropecuária Brasileira, p. 12-18. (Série Frutas do Brasil, 21), 2002.

23. PIZATO. S.; CORTEZ-VEGA, W. R.; PRENTICEHERNÁNDEZ, C.; BORGES, C. D. Efeito da aplicação de diferentes revestimentos comestíveis na conservação de maçãs 'Royal Gala' minimamente processadas. Journal Semina: Ciências Agrárias, v. 34: p. 253-264, 2013. DOI 10.5433/1679-0359.2013v34n1p253

24. DAMASCENO, K. S. F. S. C.; ALVES, M. A.; MENDONÇA, S. C.; GUERRAS, N. B.; STAMFORD, T. L. M. Melão minimamente processado: um controle de qualidade. Ciência e Tecnologia de Alimentos, v. 25: p. 651-658, 2005. DOI 10.1590/S0101-20612005000400005

25. LIMA, L. C.; COSTA, S. M.; VIEITES, R. L.; DAMATTO JÚNIOR, E. R. Effect of ascorbic acid on "orange flesh" fresh cut melon. Alimentos e Nutrição, v.22: p.291-299, 2011.

26. ARRUDA, M. C.; JACOMINO, Â. P.; KLUGE, R. A.; AZZOLINI, M. Temperatura de armazenamento e tipo de corte para melão minimamente processado. Revista Brasileira de Fruticultura, v. 25 , p. 74-76, 2003. DOI 10.1590/S0100-29452003000100022 